\title{
Crónica legislativa
}

Período: De febrero a junio de 2015

Nicaragua

Neylia Abboud Castillo

mde2009@ns.uca.edu.ni

Profesora titular de la Universidad Centroamericana, Nicaragua

Ley No. 899, Ley de sociedades de inversión, publicada en La Gaceta, Diario Oficial No. 76, de 27 de abril de 2015 y aprobada por la Asamblea Nacional, el I5 de abril del 20 I5.

Este cuerpo normativo regula la constitución, autorización, funcionamiento, supervisión, fusión o adquisición y liquidación de las sociedades de inversión. Define como sociedades de inversión a “... las entidades especializadas en realizar operaciones financieras, para promover la creación o ampliación de empresas o financiamiento de proyectos para las diversas actividades productivas, comerciales y de infraestructura del país, en sectores tales como, energético, inmobiliario, infraestructura vial, desarrollo municipal; mediante la captación y canalización de recursos internos o externos de mediano y largo plazo. Los recursos obtenidos podrán ser invertidos, ya sea en forma directa, adquiriendo acciones o participaciones; o en forma indirecta, otorgando créditos para la reorganización, desarrollo, o fusión empresarial así como aquellos proyectos, que promuevan el desarrollo de las actividades y sectores antes señalados”. Su propósito es dinamizar el mercado de inversiones en el país, trayendo consigo varias opciones que permitan implementar una mejor economía de crecimiento, promoviendo las inversiones de gran magnitud. El ente regulador encargado es la Superintendencia de Bancos y otras Instituciones Financieras. Esta ley deroga el Capítulo II del Decreto $N^{\circ}$. I5-L, Ley Especial sobre Sociedades Financieras, de Inversión y otras, publicada en La Gaceta, No. 77 del 10 de abril de 1970.

Ley No. 900, Ley de pensión reducida por vejez para las personas aseguradas por el Instituto Nicaragüense de Seguridad Social (INSS), publicada en La Gaceta, Diario Oficial No. 93, del 2 I de mayo del 2015 y aprobada por la Asamblea Nacional, el I 2 de mayo del propio año.

Esta norma crea la novedad de la pensión reducida por vejez para las personas adultas mayores, que si bien cotizaron en el INSS, no llegaron a las 750 semanas exigidas por ley para obtener su pensión completa. Dicha ley dispone que el mínimo de semanas cotizadas será de 250 y el monto de la pensión será proporcional al tiempo cotizado.

\section{Acuerdo No. 70, de 9 de febrero del 20 I 5, de Corte Plena, Corte Suprema de Justicia.}

En virtud de este acuerdo se faculta a los jueces de ejecución y embargos para ejecutar embargos y secuestros preventivos decretados por los jueces especializados de violencia. El acuerdo ratifica que los jueces ejecutores no tienen facultades para asuntos de apoderamiento y entrega de menores de edad, para cuyos casos quedan con competencia exclusiva, la autoridad judicial familiar, tal y como venía establecido desde el Acuerdo No. 34, de 8 de marzo del 2012. El acuerdo comentado, No. 70, surge para dar respuesta al exceso de trabajo que pesa sobre la judicatura especializada en violencia y la ausencia de disposiciones que facultaran al juez ejecutor llevar a efecto embargos, en ésta área. Quede 
señalado que la jurisdicción especializada en violencia es fruto de la entrada en vigencia de la Ley No. 779, "Ley integral contra la violencia hacia las mujeres y reformas a la Ley No. 64I, Código Penal”. Esta ley es posterior en el tiempo al Acuerdo No. 178, de 17 de diciembre de 2010, que creó la figura del juez ejecutor y por lo tanto, no se pudo prever en éste, las competencias para ejecutar resoluciones en temas de violencia de género. Por su parte, la ley No. 779 guardó silencio sobre el asunto y las ejecuciones terminaron recayendo sobre los propios jueces de violencia, distrayéndoles de su enfoque jurisdiccional. Es el acuerdo No. 70, en comentario, quien suple la ausencia normativa y soluciona un problema práctico en la aplicación de la norma.

\section{Acuerdo No. 78, de 19 de febrero de 2015 de Corte Plena, Corte Suprema de Justicia.}

Este acuerdo, establece el procedimiento para adquirir el Libro de Divorcio, al que hace referencia el Código de Familia, en su art. 159. Se acuerda que será únicamente la imprenta del Poder Judicial la que elaborará dichos Libros. La entrada en vigencia, en abril de 2015, del primer Código de Familia de Nicaragua, da lugar, de forma primigenia, a la figura del divorcio en sede notarial. El Libro de Divorcio, a que se refiere el acuerdo en comentario, se entregará únicamente a Notarios públicos que tengan al menos 10 años de estar incorporados para este ejercicio. En Nicaragua, el sistema del notariado es numerus apertus e inicia, tras una juramentación que realiza el licenciado en ciencias jurídicas, ante la Corte Suprema de Justicia, lo que se tiene por incorporación.

El tema sobre cómo instrumentar notarialmente el acto jurídico del divorcio generó polémica en la comunidad jurídica nacional porque, aunque la naturaleza del acto mismo no deja márgenes de dudas, en hermenéutica jurídica, para entender qué se trata de una escritura pública, lo cierto es que el Código de Familia emplea indistintamente, dos términos: escritura y "libro a la manera del de matrimonio", que resulta ser un Libro de Actas. El empleo indistinto de estos términos, unido a una histórica práctica notarial de documentar en libro de actas al matrimonio, introdujo un fundado debate jurídico que se decantó por el comentado acuerdo, que crea el Libro de Divorcio, como protocolo independiente del Notario, pero que se integra, no por Actas, sino por escrituras públicas.

Quede dicho que, instrumentar en Libro de Actas el matrimonio, aunque en contradicción con la doctrina notarial, tiene amparo en la "Ley que le da Mayor Utilidad al Notariado" la que lleva un germen equívoco, por inexacta traspolación del Derecho canónico a la sede civil: instrumentar mediante acta (que hace el párroco celebrante) lo que corresponde a escritura pública - manifestaciones de voluntad de las que da fe el notario. Las reflexiones jurídicas que generaron este debate merecen mayores líneas a estas, lo que, por la naturaleza de este espacio, se hace imposible honrar.

\section{Instrucción del Consejo Nacional de Administración y Carrera Judicial de la Corte Suprema de Justicia, de 8 de mayo de 20 I5.}

Esta instrucción aclara que los jueces de Distrito Civil mantienen la competencia para conocer y resolver asuntos de rectificaciones y reposiciones de partidas de nacimientos. Esta aclaración se hizo necesaria porque la entrada en vigencia del Código de familia, en abril de 2015, generó la inquietud de los jueces civiles, sobre si las competencias que tenían atribuidas para asuntos de nombres de las personas, quedaban tácitamente derogadas por la disposición del art. 425 inciso s) del referido Código, que dice: "... la jurisdicción de familia conocerá... cuestiones relativas al nombre, inscripciones de nacimientos, estado civil y capacidad de las personas...”. La instrucción esclarece que en sede familiar se conocerá de 
estas materias cuando estén conectadas con asuntos principales de familia, en caso distinto, los Jueces de Distrito Civil mantienen las competencias en la materia, conforme establecen los arts. 566 y 578 del Código Civil de Nicaragua, de 1904.

Instrucción del Consejo Nacional de Administración y Carrera Judicial de la Corte Suprema de Justicia, de 25 de junio de 20 I5.

Esta instrucción aclara que a todo escrito de demanda en asuntos de familia, deberán adjuntarse, además de tantas copias como demandados haya, otras copias para el Ministerio de la Familia y la Procuraduría Nacional de la Familia. Ambas son instituciones a ser oídas en todos los procesos de esta naturaleza. También, la instrucción esclarece que el tiempo que demoren los resultados de las pruebas periciales, bien sea, por fuerza mayor, caso fortuito, o imposibilidad de evacuarla, no será imputable al juez familiar, para efectos de establecer la responsabilidad administrativa que ordena el Código de Familia, ante la inobservancia de los términos procesales establecidos en él.

Por último, quede apuntado que, en la primera mitad de año 20I5, se aprobó el nuevo Código Procesal Civil, de la República de Nicaragua, que derogará a su antecesor de 1914. A la fecha se espera su sanción por el poder ejecutivo, promulgación y publicación, en La Gaceta, Diario Oficial. 